\title{
Feasibility, Functioning and Future of MPAs in Mainland Tanzania: Evidence from Two Marine Parks
}

\author{
Simeon Mesaki* \\ Department of Sociology and Anthropology, University of Dar Es Salaamm, Tanzania
}

*Corresponding author: Simeon Mesaki, Department of Sociology and Anthropology, University of Dar Es Salaamm, Tanzania.

Received Date: February 20, 2020

Published Date: March 03, 2020

\begin{abstract}
Marine protected areas $\left(\mathrm{MPA}_{\mathrm{s}}\right)$ are a key tool that Tanzania has committed in protecting and conserving its marine biodiversity and intervention for coastal underdevelopment. The idea of establishing Marine Parks and Reserves in the country became a reality through the Marine Parks and Reserves Act (MPRA) of 1994 which provides for the legal framework for conservation, management and wise-use of coastal and marine resources. Currently Tanzania mainland has three marine parks and fifteen reserves established under the MPRA; their management mandate to the semi-autonomous Marine Parks and Reserves Unit (MPRU). The paper assesses the rationale of establishing these forms of conservation and developmental initiatives, amplifying their lackluster performance in achieving stated goals and the future prospects compared to the more successful terrestrial national parks.
\end{abstract}

\section{Background}

\section{Marine Protected Areas (MPA)}

Marine Protected Areas $\left(\mathrm{MPA}_{\mathrm{s}}\right)$ are recognized as management instruments to protect marine biodiversity, to maintain or restore ecosystem health, and to provide coastal communities with a sustainable source for economic growth. A marine protected area is defined by the International Union for the Conservation of Nature (IUCN) as any area of intertidal or sub tidal terrain, together with its overlying water and associated flora, fauna, historical, and cultural features, which has been reserved by law or other effective means to protect part of or the entire enclosed environment (WIOMSA, n.d.). The marine and coastal resources of Tanzania support local communities and contribute to the national economy, but these resources have come under increased pressure due to overfishing, destructive fishing practices, mangrove deforestation, pollution and unregulated tourism posing considerable environmental and socioeconomic strains. There are many different types of MPA, ranging from "multiple-use" to 'no-take' and even to 'no use' areas. MPA are established and managed for a range of objectives. In Tanzania, all
$\mathrm{MPA}_{\mathrm{s}}$ are multiple use areas with one key objective being improved livelihoods for communities within the MPA [1].

\section{Critique}

Kuboja [2] commends the establishment of $\mathrm{MPA}_{\mathrm{s}}$ but also cautions on their high expectations. Thus, he writes.......It is hoped that MPA may allow for a more sustainable management of resources particularly in ways that can benefit the poor and provide them with a strong base for economic growth and hence pathways out of poverty. MPA $\mathrm{s}$ are expected to allow for improved efficiency in the management of coastal and marine resources, in order to increase their contribution to all levels of the national economy, including at community level where the impact of declining resources is felt most". At the same time, he argues that in many instances maximizing economic and conservation benefits simultaneously in $\mathrm{MPA}_{\mathrm{s}}$ has proven to be unrealistic and resulting in collective action problems, which has led to Tanzania abandoning the "no take area concept". 


\section{Existing $\mathrm{MPA}_{\mathrm{s}}$ in mainland tanzania}

Out of the $32,000 \mathrm{~km}^{2}$ of the territorial sea of Tanzania Mainland, 2,173 $\mathrm{km}^{2}$ (about 6.5\%) has been gazetted as MPA s $_{\text {[ }}$ ] and it is projected that by 2020 , at least $10 \%$ of coastal and marine areas, particularly areas for biodiversity and ecosystem services, are conserved and effectively and equitably managed (URT, ibid). There are currently 3 Marine Parks and 15 Marine Reserves as the table below shows:

Table 1: List, Size \& Year of Establishment of Marine Parks and Reserves [3].

\begin{tabular}{|c|c|c|}
\hline MPAs Gazetted Under the MPRU & Year & Area $\left(\mathrm{km}^{2}\right)$ \\
\hline Mafia Island Marine Park (MIMP) & 1995 & 822 \\
\hline Mnazi Bay Ruvuma Estuary Marine Park & 2000 & 650 \\
\hline Tanga Coelacanth Marine Park & 2009 & 552.17 \\
\hline Mbudya Island Marine Reserve & 1975 & 14.22 \\
\hline Bongoyo Island Marine Reserve & 1975 & 9.15 \\
\hline Pangavini Island Marine Reserve & 1975 & 2.13 \\
\hline Funguyasini Marine Reserve & 1975 & 22.9 \\
\hline Kendwa Island Marine Reserve & 2007 & 5.3 \\
\hline Sinda Island Marine Reserve & 2007 & 1.8 \\
\hline Makatube Island Marine Reserve & 2007 & 7.78 \\
\hline Shungumbili Island Marine Reserves & 2007 & 4.2 \\
\hline Nyororo Island Marine Reserve & 2007 & 21 \\
\hline Mbarakuni Island Marine Reserve & 2007 & 3.8 \\
\hline Maziwe Marine Reserve & 1975 & 4.5 \\
\hline Kirui Island Marine Reserve & 2010 & 36.1 \\
\hline Ulenge Island Marine Reserve & 2010 & 3.16 \\
\hline Mwewe Island Marine Reserve & 2010 & 0.4 \\
\hline Kwale Island Marine Reserve & 2010 & 12.13 \\
\hline
\end{tabular}

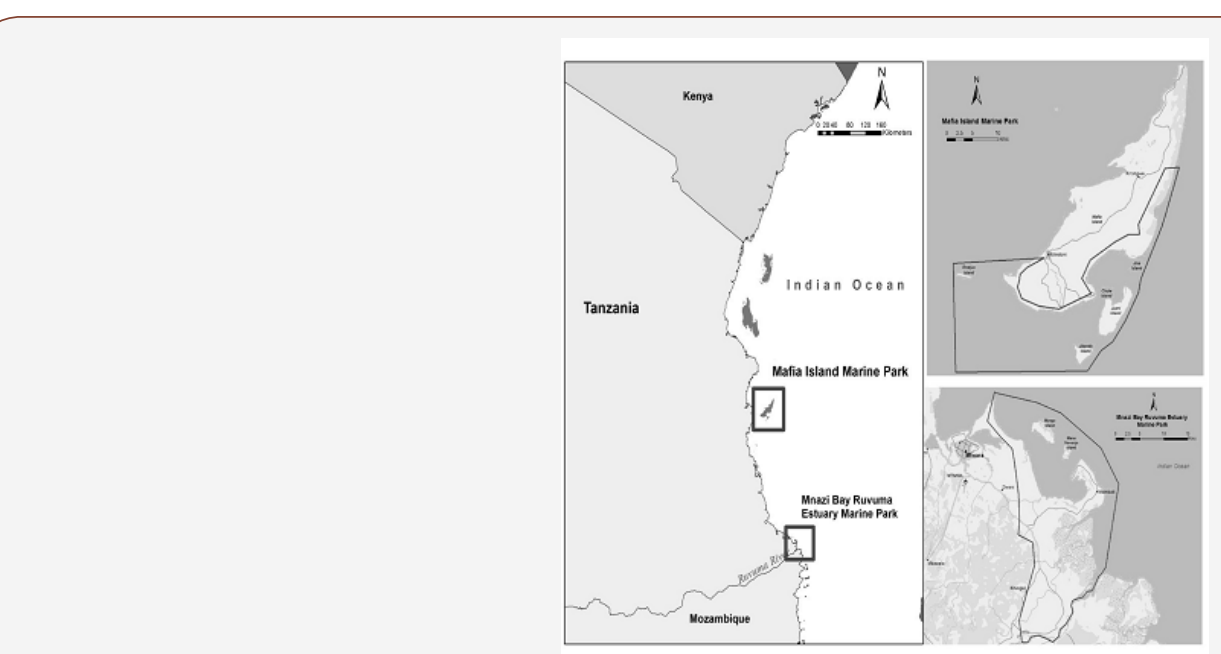

Figure 1: Map showing the two Marine Parks [17]

\section{Legal, institutional and regulatory frameworks}

Marine parks and reserve act no. 29 of 1994: The keystone legislation related to $\mathrm{MPA}_{\mathrm{s}}$ in Tanzania is the Marine Parks and Reserves Act No. 29 of 1994 and the Marine Parks and Reserves (Declaration) Regulations of 1999. They operate within the context of national environmental and fisheries policies for the protection of natural resources and the fisheries sector. The Act has two overriding objectives: i) to protect, conserve and restore the species and genetic diversity of living and nonliving marine resources as well as the ecosystem processes of marine coastal areas; and ii) to ensure that communities and local users of resources are facilitated to engage in the planning, development and management of an MPA, and that they share in the benefits of the operation of the PA and have priority in the resource use and economic opportunities 
afforded by the establishment of the marine park or reserve. In addition, the following legal and policy instruments apply in one way or another in relation to MPA.

Marine Parks and Reserves Unit (MPRU): The Marine Parks and Reserves Unit (MPRU) is a quasi-independent governmental entity under the Ministry of Livestock and Fisheries. Though physically separate from the department it falls under their oversight. It is to be noted that originally it was under the Ministry of Tourism and Natural Resources, then moved to the ministry of Agriculture, Livestock and fisheries before its new "home". Established under the Marine Parks and Reserves Act of 1994 it has the objectives, the achievements of which are guided by the following strategies:

1. Have legal tools for smooth management of MPA.

2. Publicize and disseminating $\mathrm{MPR}_{\mathrm{s}}$ information (e.g. regulations) to all stakeholders.

3. Establish and maintain boundary development in all MPR.

4. Develop and establish an effective revenue collection system in all MPA.

5. To undertake 5 year strategic Planning exercises including Midterm and Long Term Financing strategies to reduce excessive dependency on government funding.

6. Improve the economic welfare of the local communities living inside $\mathrm{MPR}_{\mathrm{s}}$ by promoting ecologically, socially and economically acceptable practices.

7. Develop and maintain open and consultations between the Board, $\mathrm{MPR}_{\mathrm{s}}$ management, LGA and other stakeholders in relation to institutional arrangements, mandates and administration.

Misgivings about governance of MPA : Mangora et al 2012 have identified the institutional challenges in implementing legislation with respect to $\mathrm{MPA}_{\mathrm{s}}$. In the main they argue that the implementation of the laws has floundered due to inherent problems that undermine the capacities of most institutions to implement the laws. These include: i) Budgetary constraints as most of the institutions are state owned and depend entirely on government subventions, ii) Inadequate personnel, resources and technical capacity; Lack of information sharing; and iii) Lack of institutional coordination (e.g. while there are provisions in the MPR Act and National Parks Act of transforming MPAs into national parks, there is supposedly no collaboration between MPRU and TANAPA regarding coastal and marine managed areas, seen as critical for formulation of networks that may involve bringing together Protected Areas (Ps) that fall under different jurisdictions. It is concluded that although there is a general positive trend in the reform and development of laws and policies at the national level to support integrated coastal management and $\mathrm{MPA}_{\mathrm{s}^{\prime}}$ most of the legislative provisions are essentially still sectoral and largely uncoordinated. On the other hand, Kuboja 2013:263 points to the fact that the Marine Parks and Reserves Act does not make provisions for application of customary laws and practices by coastal communities that for example exclude outsiders and traditional enforcement of resource use principles. Where these customary laws or practices are consistent with MPA laws, they form the basis for community support. As early as 1998, a task force [4] had found that "the economic, social and conservation benefits of MPRs are constrained by problems related to institutional and legal set up for effective governance." The MPRU in particular was seen as "not able to effectively and efficiently execute its main reasons being that it is a government unit with multiple reporting structure, legally overlapping mandates (the Board of Trustees and the Director of Fisheries). The Task Force recommended the transfer of the MPRU to TANAPA, as it was seen as the most feasible and cost-effective in terms legislative and administrative changes required and accommodated the participatory elements of the MPR Act 1994. The least desirable option was then retaining the status quo of the MPRU. However, as no political decisions were taken for a change, the status quo remained up to now. Andrews the Marine Parks and Reserve Act of 1994 was modelled on the international paradigm of Integrated Coastal Zone Management (ICZM), of which marine parks are considered a key tool. He points out that the act does little to integrate decision-making, if anything, it adds additional layers of administration as it entails the formation of a Board of (BoT), a Marine Parks and Reserves (MPRU) within the Departmnet of Fisheries (DoF), at a time when the Government was trying to downsize its public service to meet International Monetary Fund (IMF) arrangements and adopt decentralization.

\section{The Case Studies}

In this paper, using documented evidence, makes use of scholarly works of social and marine science on Mafia Island Marine Park (MIMP) and Mnazi Bay-Ruvuma Estuary Marine Park (MBREMP) to explicate the aim stated in the abstract, that is, the rationale of establishing MPA of conservation and developmental initiatives, amplifying their lackluster performance in achieving stated goals and the future prospects.

\section{Mafia Island Marine Park (MIMP)}

MIMP was the first MPA to be established in 1995. It was chosen because of its unique ecosystems, covering the southern coast of Mafia Island, including four small inhabited islands of Chole, Juani, Jibondo and Bwejuu as well as uninhabited rocky islets, reefs and sandbars. The direct 'user' population of the marine park then was around 18,000 residing in the 11 villages (currently they over $20,000+$ ). The goal of MIMP as stated in the original General Management Plan (GMP) of 2000 is to conserve the diversity, abundance and function of all physical and biological resources, in order that they may continue to be enjoyed and productively utilized by present and future generations. Below I reproduce findings of authoritative authors on MIMP: Hogan, Walley Andrews, 
and Benjaminsen and Bryceson. Hogan studied perceptions of local communities, of the District government and the MIMP management, also with particular focus on participation and benefit sharing in resource management. She argues that the relationship between the park and the people is of a patron and the patronized rather than a partnership.' She notes that while in the majority of villages, most people had little or no feelings of resistance to the park, direct resource users, particularly fishers and coral harvesters, had yet to be convinced of the benefits of the park's management methods and were thus resistant to restrictions. Hogan's recommendation is to establish direct control of benefits by residents an understandable facet but one which challenges the institutional set-up and the procedures of management. She also points out how MIMP has taken responsibility for directly promoting eco-tourism rather than providing an environment for private sector initiatives, with sometimes negative consequences. In her book, Rough Waters, Walley found Chole residents, who had formerly described the marine park as "theirs", stating bluntly that they hated the park as it was threatening their livelihoods, and suggest the reasons for this included that MIMP had started to control the fishing practices of island residents themselves and had further restricted Mafia residents from prime fishing grounds, changes seen as unilaterally conceived by park officials and visiting experts with minimal involvement from residents. She maintains that, “... by 2000 the park had become an expanding and increasingly oppressive bureaucracy that residents felt threatened their very survival." Thus, there were indications that the institutional set-up created for stakeholder participation did not work adequately then. She also writes that, at the level of the general picture was that communication initially was very active and open but progressively communities felt that communication, especially the participatory type of relationship they were promised, had been seriously lacking. In a scathing appraisal of MIMP, Andrews states that the key assumption was that a protected area is the most effective tool in managing the issues related to Mafia Island and will deliver a conservation gain. He argues that significantly greater conservation gains could have been achieved had the initial focus been on determining key environmental threats with specific strategies to manage them, rather than on establishing a marine park per se. He points out that MIMP was established in the hope that it would be the best conservation tool to manage the marine resources of Mafia, but laments that there is little evidence that any other avenues for management were ever considered. He poses the following contradiction:- "We attempt to protect this 'pristine' state rather than develop strategies that manage use. This sustains the contradiction that we are managing biophysical resources rather than managing people and their use of those resources. We develop parks rather than manage people". He, notes that a park is an object with boundaries reminiscent of the earlier preservationist's notion of a 'thing' requiring protection and that conservation outcomes will be better served when the focus is on conservation as a dynamic process, where the community and other stakeholders 'do' rather than 'have' something. He observes that on Mafia Island the concept of a park encouraged battles over the 'thing', battles fought by various players in various ways: government officials competing over access to funding, Euro-American environmentalists struggling for interests and high status positions in a cutting-edge project while Mafians outside Park boundaries were jealousy and contentiousness because they were not in the Park. He takes a cue at the degree to which international conservation agencies invested in the park for the park's sake rather than for conservation outcomes, as evidenced by the fact that the project was heralded as an innovative and model project well in advance of any conservation gains. Concentration on the Park as the outcome also led to the failure to develop appropriate strategies to manage the change that implementation of the project caused. No strategies, for example, were developed to assist institutions to change from resource exploiters based on economic need, to resource managers based on sustainable use and conservation. Individuals and institutions were expected to change from centralized decision-making processes based on economic development and resource exploitation to decentralized facilitation for conservation and community development. This was to be achieved without strategies or direct funding. This inevitably led to the exploitation of funding and opportunities designated for Mafia Island. He holds that in many respects Mafia Island was the last place in Tanzania that required the sort of high level management a marine park can afford. On the conservation issues, institutional arrangements and community development processes were then required to fit the paradigm, while environmental issues became subordinate to the Park as key activities were dominated by political man oeuvres to control the new arrangements. Despite the problems, the international commitment to the Park was based on the continuing assumption that if the institutional framework and Park were established, then conservation gains would be forthcoming. He contends that the conservation issues of concern to the Mafia Island communities, the managers and scientists, could have been adequately addressed within existing institutions and frameworks. He says the Park, as a predetermined and prescribed outcome, significantly limited the effective achievement of actual conservation gain, as there was no power or decision-making delegated to the community or independent entities. In addition, there were no mechanisms within the project to ensure accountability or effective conflict resolution. There were no mechanisms for the individual donors to communicate or make funding decisions as a coordinated body. Also funding arrangements were independent of each other, a situation which was ruthlessly exploited with many elements of the project receiving dual funding with conflicting objectives. He bemoan that, while developed countries have the time and resources to commit to various ideals of conservation within a global context, the fisher, coral miner and family providers on Mafia Island have a very different perspective, disparaging the global approach to the management of tropical marine ecosystems and the international push for a representative system of MPAs which 
has no relevance to the Mafians. Pointing to the fundamental growing pains of MIMP due to the overly ambitious nature of the project, he commends an approach that incorporates shared power and real participation as well as strategies to change various inappropriate institutional and bureaucratic cultures, which however require a long-term view and entails initially addressing the actual environmental threats, whilst patiently nurturing the evolution and development of appropriate community processes, which will then translate to the development of a marine park be labelled 'a people's park', a model of community conservation. On community participation and decision-making, he thinks they are merely rhetoric failing to establish effective operational links between the key stakeholders and players a thing never achieved on Mafia Island. Thus, the formation of various committees and advisory groups was used to exclude various factions and stakeholders in the decision-making process. While some would argue that the members of these committees represented key groups, in reality this was not the case. The committees were heavily laden with bureaucrats and technocrats. For example everyone on the Board of Trustees and Advisory Committee was appointed at the national level (even the local representatives are appointed). Meetings were mostly held on the mainland and attendance was by invitation only. In many respects the new Act removed participation from the local community as many of the issues now under the Act had been previously dealt with through the District Council under the Local system. The new arrangement usurped that authority, adding another layer of bureaucracy. It is important in the early stages of any project to ensure there are checks and balances with regards to the process, and that genuine linkages with other stakeholders are developed. Mechanisms for information flow and feedback to the stakeholders are also essential. For the MIMP to have community support it was important that they were convinced about tangible economic and social benefits accruing from the project. These economic and social benefits were easily promised to encourage support for the project, but to deliver these in a sustainable manner was extremely ambitious and in many respects, he claims. The development of the MIMP and the provision of social and economic benefits to the community were in the long term to be funded from but considering the cost of the development of the MIMP and its various organs this was never going to be achievable. For one thing tourist projection figures were highly exaggerated and when it was clear that tourism was never going to be in a position to fund the park in a sustainable manner, no redress was made, thus putting enormous pressure on the fledgling and struggling tourist operators on Mafia Island who were major stakeholders but again, were rarely consulted. It was unrealistic to assume one marine park could fund the Board of Trustees, the Marine Parks and Reserves Unit and the Mafia Island Advisory Committee as well as MIMP staff, operational expenses and put money back into the community and have some left over to develop new marine parks. He concludes, "Mafia Island Marine
Park needs commitment and accountability, not rhetoric and overcapitalization". Benjaminsen et al [6] start by pointing out that statements about community-based conservation and comanagement had meaning in the consultative period prior to the formation of MIMP, and in the initial period of collaboration with villagers to successfully combat dynamite fishing, but in subsequent years, community-based conservation has become mainly rhetorical as well as authoritarian in implementation as meetings between the village liaison committees (VLCs) and the park became less frequent. Some villages were branded as uncooperative or troublesome and the MIMP leadership has not visited these places for several years, an attestation to a predominant failure of their proclaimed policy and practice of co-management. The GMP was scheduled for review in 2005 with participation of district authorities, hoteliers, conservation organizations, and villagers, but this was not carried out until 2011. During this exercise few complaints were raised openly by fisher-folk, but afterwards some villagers expressed that they felt that MIMP was not willing to listen to opposing views, and they felt intimidated by MIMP's Enforcement Unit. One village did, however, voice strong criticisms and declared their wish to be excluded from the Park altogether. Three luxurious and exclusive foreign-owned tourist hotels have been established in close proximity at Utende and Chole. Land was appropriated from villagers, fences erected and access to beaches and landing sites progressively strictly hindered. Snorkeling and SCUBA-diving tourism facilities were also established in parallel and operated by hotel-linked and foreign-owned enterprises to the exclusion of attempts by locals to operate such tourism services on a small-scale basis. The owners of tourist hotels within MIMP are foreigners. The Tanzanian state gains entrance fees from tourism and various license payments from the hotels, but in contrast to the case for wildlife tourism and hunting safari operations, there seems to be little evidence or published accounts of rent-seeking by state officials in relation to marine and coastal tourism, diving operations or game-fishing sectors in Mafia Island beyond multiple rumored instances of petty corruption. Park fees are collected from tourists as they enter the MIMP area, currently $\$ 20$ per day, and it was originally promised that villagers resident within the park boundaries would benefit substantially from a portion of these fees, but the villagers and their representatives have become disenchanted because they feel that even this process is nontransparent and they witness little tangible benefit. A small number of Mafia residents have gained markets to sell products and services to the hotels and to MIMP staff-a few actually gained opportunities for employment - but there are less than 200 persons employed by the tourist hotels. A small number of Mafia residents provide lowcost guesthouse facilities for visiting researchers, but the betterpaid jobs in the marine park administration and the tourism hotels have been awarded entirely to Tanzanians from outside Mafia Island or to foreigners. The key problem with the intervention of the park from the point of view of residents of Mafia Island as 
expressed in meetings and interviews (2006 to 2012), was that the benefits clearly accrued mainly to the State, to foreign-owned tourism enterprises, to conservation organizations and to visiting foreign tourists, whilst local communities witnessed few gains. This was felt to be in direct contrast to the fact that villagers have lost access to formerly traditionally governed and utilized natural resources (including the most productive coral reefs, mangrove forests and the best beaches), without gaining commensurate economic compensation for losses in fishing rights and land or seascape rights, or being allowed, for example, to make some income by taking visitors on guided tours or snorkeling. Fisher folk and villagers from within the park repeatedly expressed disappointment and skepticism about the increasingly exclusive practices of both conservation and tourism for these reasons.) Supported by WWF's East African Marine Eco-region programme, MIMP embarked upon a pilot programme for exchanging fishing gears. Citing to Ngusaru (2003) [6] quote, 'This was envisaged as part of a wider strategy to promote alternatives to fishing gears such as seine nets, which are considered by MIMP and WWF to be destructive and to lead to over fishing, although there are no substantial fisheries data to support these claims'. The gear exchange programme provided large-meshed gillnets and collapsible fishing traps to fishers at Juani and Chole villages inside the marine park. Some local fishers initially responded to this opportunity, but many have become increasingly skeptical due to the low catches and long periods that they have to spend travelling to more distant fishing grounds, signifying that these so-called alternatives actually constitute a major loss in their means of production and a threat to their livelihoods. WWF claimed that fisherfolk were seeing land-based agriculture as the new 'Big Idea', and suggested beekeeping on the small island of Juani within MIMP as being a significant success story. However, the 'alternative livelihood' production of honey is tiny and the income is of low significance to the small community of Juani island in the villagers' own estimation, since this provides a minor supplementary income to only six people: whereas it is claimed by Mgeni that in all the villages within the MIMP area, 40 to 150 people (less than $1 \%$ of the residents) individually earn up to USD 0.60 per day. During 20002004, WWF and MIMP launched an Environmental Education Strategy and Action Plan in order 'to educate and train people to deal with major environmental problems such as degradation of ecosystems, depletion of natural resources, loss of biodiversity, soil, water and air pollution and haphazard urbanization and industrialization'. Again, while sympathizing with conservation goals per se, many villagers viewed this as reinforcing restrictions on their daily livelihood activities and presenting few if any avenues for economically viable alternatives. The villagers increasingly feel, and actually are, dispossessed of their lands and resources, and even unwelcome in their ancestral home areas due to hostile actions by tourist operators, such as abusive language and cutting of anchor ropes, and steadily more repressive measures taken by the MIMP Enforcement Unit authorities. In relation to marine and coastal conservation, it appears that the proclaimed approaches of people's participation and community-based conservation that were highlighted and initially honored during the $1990^{\text {s }}$ have been replaced by a more protectionist, authoritarian practice of conservation in recent years. Some villagers feel that they are losing key land rights to rich tourism enterprises as well as their rights of access to vast areas of the most productive marine resources, which they consider themselves to have traditionally governed and utilized sustainably in the past.

\section{The Mnazi Bay-Ruvuma Estuary Marine Park (MRBEMP)}

Rationale: Located south of Mtwara town MBREMP was gazetted in 2000 as the second such park after MIMP. MBREMP has 11 villages within its boundaries that border Mozambique. With a total area of $650 \mathrm{sq}$. km. including the northern portion of the Ruvuma Estuary, Mnazi Bay and the islands of Namponda, Membelwa and Kisiwa Kidogo. The MPA was designated for a number of reasons including: good representation all the marine habitats found along the shores of Eastern Africa, highly productive and diverse fisheries and promising potential for coastal tourism and reserves of gas. The MBREMP is unique in that its land to marine ratio is the highest in East Africa. It ranks among the highest diversity sites for corals in East Africa, and very high levels of recruitment of hard and soft corals have been observed. At the same time, it displays among the highest indicators of overexploitation and destruction. The ecosystem as a whole, and in particular the fish communities, were highly degraded due to excessive exploitation. On the positive side, the high apparent resilience of the reefs means that management measures may be very successful. The MBREMP provides nesting sites for endangered green and critically endangered hawksbill turtles. Dolphins occur in the park throughout the year, and sperm and humpback whales are seen during migration. The mangroves of the Ruvuma Estuary appear to be among the best mangrove forests in Tanzania. The park is also classified as an Important Bird Area because of the high densities it supports of migrating crab plovers. The local context was couched in the following manner. Mtwara District is among the poorest in Tanzania. Approximately 28,000 people live within the boundaries of the marine park, in ten villages and seven sub-villages. According to a socio-economic study carried $35 \%$ of the MBREMP households exploit the marine resources, and of the seafront communities, 50-60\% of the households are involved in marine resource activities. Most resources were perceived to have declined in the previous ten years. The Goal of the project was to enable local and government stakeholders to protect effectively and utilize sustainably the marine biodiversity and resources of Mnazi Bay and the Ruvuma Estuary (2014).

\section{Risks and constraints}

1. Stakeholder support for and participation in management activities may decline after project completion.

2. Co-operative arrangements between communities and the MPRU may break down. 
3. Concern about the size of the project team in relation to the ambitions of the project

4. There may be inadequate revenue to meet ongoing management costs.

5. People's economic opportunities are constrained by weak social organization and the difficulty to access funds/capital.

6. A potential threat was the Artumas gas field development and energy generation project within the park

\section{Start Up}

After gazettement of the park in 2000, the MPRU began putting staff in place, but without project funding. So, it started on a bad foot as it did not have the means to meet the high expectations that had arisen in the local communities and local government during the project development period. According to the work plan in the project document, work was to have started in July 2001, but the project document was not signed until April 2002, and funds were first transferred from UNDP to IUCN in July 2002 and as such it started a year later than planned, and two and a half years after the gazettement of the park. This delay had serious implications for implementation and is one of the root causes of the problems linked to high expectations encountered in the initial phase. The long delay in the availability of funds was very prejudicial to the accomplishment of the objectives.

\section{Evaluations and reviews}

Midterm: In the midterm review [7] it was observed that the project was being implemented through a rather complex, and not so easy, partnership among the MPRU, UNDP, IUCN, FFEM, and the park in Mtwara. In addition, lack of clarity in the roles and responsibilities of the partners hindered smooth project implementation and although relations had improved, there was still unnecessary overlap in responsibilities when in fact ideally the project partners should all be fulfilling different-and complementary-roles. It was also pointed out that the project had been wildly ambitious (emphasis mine). On the park's relations with local communities the reviewers were of the opinion that they were fragile, at best. The review called for a good relationship between the MBREMP and communities within the Park because it was an essential ingredient in MBREMP achieving its objectives.

Terminal Evaluation: Approaching the evaluation from the UNDP Handbook on Monitoring and Evaluation and the ToRs and consultations with UNDP Tanzania, the final (Tortell, et al, 2007) found the project concept basically sound and the design fine in principle. It was found that project management was generally effective in both phases but suffered through the hiatus created between the two phases of implementation. Though it seemed there were two "managers" (Project Manager and Technical Adviser) with overlapping responsibilities and unclear roles during the First Phase apparently it did not affect project delivery.
Evaluiation team rated the various components of the project as follows:

1. Progress towards Outcome 1 (Knowledge base) has been satisfactory with an adequate technical base established for Park management. More work is required especially on the social dimension.

2. Progress towards Outcome 2 (Awareness) has been marginally satisfactory and more work is required.

3. Progress towards Outcome 3 (Planning and Monitoring) had been satisfactory in terms of both planning/monitoring though the latter requires some more work.

4. Progress towards Outcome 4 ((Management Plan) is considered marginally satisfactory even though the Plan has been prepared. This rating is the result of the Indicators selected and the extent of project progress towards them.

5. Progress towards Outcome 5 (Capacity) has been satisfactory. On the basis of the Indicators, this Outcome should be rated as unsatisfactory; however, our understanding of the real situation leads us to assign the satisfactory rating.

6. Progress towards Outcome 6 (Alternative Incomes) is considered marginally satisfactory and more work is required particularly at the commercial end of the operations.

7. Only Outcome 1 has a set of relevant and useful Indicators-the rest range from inappropriate to inadequate to unnecessary. The Team believes that most Indicators were not very helpful to the PMU and recommends greater attention to Indicators in future project planning.

8. More objective analysts: Katikiro $\mathrm{R}$ et al [8] start with looking at the original goals of the marine park as contained in the GMP and point out the fact that the GMP mentions benefitsharing it does not include livelihood diversification and the wellbeing of the affected community in its management objectives (cf. 2011: viii-ix). They point out that these issues are only mentioned in passing elsewhere in the text and the only benefits explicitly mentioned are those coming from gas exploitation and eco-tourism. These are supposed to compensate for the curbing of existing economic activities (Ibid: ix). Much of the focus of the GMP is on 'education' of local communities, sometimes in fairly patronizing ways. The GMP mentions the existence of a 'tourism investment framework', but no tourism investments have been carried out so far in the MBREMP area. The GMP was produced in 2005, with a revised version published in 2011. While the MBREMP midterm evaluation report [7] submitted to IUCN recommended that enforcement cannot be done without alternative income generating activities, the livelihood component in the GMP has remained vague. In addition they found that the VLCs have become virtually dormant as they lacked motivation to 
fulfil their duties, and that the reality behind family ties and social hierarchy in villages makes the unbiased and proper functioning of VLCs difficult (muhali in the coastal milieu). Ineffective execution of sustainable management of fishery resources by VLCs is also attributed to the limited impact they have had on decision making on abiding to regulations. Lack of adequate funding and resources needed for monitoring and control also hindered VLCs from curbing destructive fishing activities and other violations in their areas of jurisdiction.

9. The work by Mangora et al. compare three villages located within MBREMP (Msimbati, Litembe, Mahuranga) and two outside. They argue that the MPA limits livelihood choices and activities without offering alternative benefits and safety nets they show that villages outside the MPA are actually doing better than those inside. They also observe community resistance to MBREMP, highlight lack of community participation, and report accusations by villagers that MBREMP is seizing their user rights and tenure. They see no clear livelihood benefits arising from MBREMP, and no provision of extra social services or improvements that could be attributed to the MPA. They report that three pilot projects on alternative livelihoods had been established, but they were placed in interior villages, where the impact on restricting resource access is less severe than in coastal villages where opposition to MBREMP has been more marked. By the time of their fieldwork, these livelihood diversification projects seemed to have collapsed. Finally, they mention a planned ecotourism investment in Litembe and a general lack of clarity among the communities living next to the entrance gate on how entry charges are collected and what they are used for.

10. Mwanjela and Lokina focus is on community participation. They highlight severe power struggles between the MPA and local communities in managing resources and in terms of distribution of benefits. They argue that donors had much stronger influence on the creation of MBREMP than the Tanzanian government or local communities. They highlight the severity of fishers' main complaints:

1. Dugout canoes cannot reach the fishing grounds further ashore, which are outside of the MBREMP area; and access to modern boats was promised but never materialized.

2. Exchange of illegal fishing nets with legal nets never happened; and

3. Alternative income activities never took off; some were based on activities that are not customary in the areas, such as beekeeping. They also report conflicts over patrolling and the use of police force instead of park officers. At the community-level, they underline that Msimbati (the largest village within MBREMP) used to be a major trade Centre - with important sales to octopus and sea cucumber, which are now protected by the MPA; and that women can no longer collect bivalves for own consumption. They conclude that community participation in MBREMP has been only rhetorical and claim that: village governments are more powerful than $\mathrm{VEC}_{\mathrm{s}} ; \mathrm{VEC}_{\mathrm{s}}$ are a loophole for village elites to capture benefits via meeting allowances; and communities are treated simply as recipients of MPA rules. Similar results are reported in previous studies by Mwanjela (2011), who highlights the negative impacts of restrictions to resource access, the confiscation of fishing gear, and the lack of delivery of promised benefits (gear, motorized boats, alternative livelihood initiatives) and by Kamat, who shows the top down nature of implementation of activities by MBREMP, which led to an increase in structural violence and deepened inequality. Kamat (2014) argues that lack of tangible benefits, lack of consultation with villagers, and restricted access to resources is causing suffering [8] examine the limitations of MBREMP in moving from a state-led initiative towards a more 'locally-managed marine area' (LMMA). They argue that LMMA in Tanzania are hampered by top-down procedures and lack of community involvement in their establishment. Marine park legislation is not clear on how $\mathrm{NGO}_{s}$ and private stakeholders can be involved in management (although this is now under review). Katikiro et al. [8] focus on perceptions related to promoting local management and participation. They report insufficient participation by 'legitimate community representatives' and strong interference in implementation from MPRU, IUCN Eastern Africa Marine Programme, UNDP/GEF and the French Global Environmental Facility (FFEM). Community participation took place mainly at village-level at public meetings, with little representation at district-level meetings. They conclude that there has been a rapid increase in management of marine resources, but that MBREMP has failed to move from centralized to community based management. In a related study, Katikiro et al. [8] highlight how conflict within MBREMP can also be characterized along political party lines.

\section{The Future}

The marine parks and reserves are under the auspices of the Marine Parks and Reserves Unit of the Ministry of Livestock and Fisheries. Their continued existence and sustainability depends on how this unit comes to grips with the numerous problems it has been facing, one of them being its shift from the original "appropriate" location in the Ministry of Natural Resources and Tourism and continued dual reporting relationship and an unclear chain of command. In its 2014-2019 Strategic Plan MPRU identifies its strengths and weaknesses. Among the weaknesses are: some ambiguities in the MPR Act, inadequate autonomy as provided by the Act, conflicting and/or overlapping mandates of the institutions in the Act, emerging issues which need to be reflected in the Act e.g. management and protection of fresh water biodiversity, inadequate skills in planning, management and monitoring of $\mathrm{MPR}_{\mathrm{s}^{\prime}}$, inadequate awareness and outreach programmes, inadequate number of skilled, un-updated mechanism to engage voluntary and honorary staff and inadequate awareness creation. Of course, one of the stumbling blocks against proper functioning 
of MPRU is the withdrawal of donor funding and insufficient government subventions. The Controller and Auditor General (CAG), has since 2013 pointed to the fact that MPRU has been running at a loss and that its liabilities exceeded its assets below the ideal ratio of $2: 1$, concluding that there was, “...significant doubt as to the ability of the unit to smoothly continue to sustain its daily operations without additional financing from government or other sources of financing". In its 2018 Audit Report on MPAs, the CAG found among other weaknesses of the MPRU being inadequate control of investment and inconsistencies and unreliable revenue sharing with local communities and districts. It advised MPRU to develop practical guidance on how parks are to assess economic opportunities to determine their compatibility with the conservation objectives of the MPAs, citing the economic activities taking place in Marine Parks and Reserves including gas exploitation in MBREMP and tourism infrastructure in MIMP and Dar es salaam Marine Reserves System(DMRS), stressing the importance of these activities to be compatible with the conservation objectives of the MPAs. It is interesting to note that despite the above the Borard of Trustees, in on of its reports consoles itself by stating that, it has, "... reasonable expectation that the MPRU has adequate resources to continue in operational existence for the foreseeable future" (CAG, 2017:2) and claiming it has no reason to believe that the unit will not be a going-concern (sic) in the foreseeable future based on forecasts and available cash resources (CAG, 2017:12).

\section{Acknowledgement}

None.

\section{Conflict of Interest}

No conflict of interest.

\section{References}

1. Meyers D (2014) Technical support to project preparation: assessment of potential role of marine protected areas in SWIOfish Tanzania project.
2. Kuboja B (2013) Policies and legal frameworks for MPAs governance in Tanzania mainland: their potential and limitations for achieving conservation and livelihood goals.

3. URT (2015) National Biodiversity Strategy and Action Plan.

4. Ngoile M, Makoloweka Melamari (1998) MNRT, Report on the Future of the Marine and Reserves Administration in Tanzania Tortell. Pand and Ngatunga, B Terminal Evaluation of MBREMP.

5. Andrews G (1998) Mafia Island Marine Park Tanzania: Implications of Applying a Marine Park Paradigm in a Developing Country ITMEMS. Proceedings pp.267-279.

6. Benjaminsen T, Bryceson I (2012) Conservation, green/blue grabbing and accumulation by dispossession in Tanzania. Journal of Peasant Studies 39 (2).

7. Gawler M, Mhando C (2004) Mnazi Bay-Ruvuma Estuary Marine Park. Mid-term Evaluation Final Report.

8. Katikiro R, Kweka O, Namkesa F, Ponte S, Minja R (2017) Sustainability Partnerships for the Governance of Coastal Resources in Tanzania. NEPSUS Working Paper 2017/5.

9. WIOMSA (n.d.) Managing Marine Protected Areas: A TOOLKIT for the Western Indian Ocean.

10. Mangora M, Shalli M, Mclean B (2012) Legal and Institutional Framework for Effective Management of Marine Managed Areas in Tanzania: Report on Mainland Tanzania.

11. Walley C (2004) Rough Waters Princeton University Press.

12. Hogan R (2003) Preparation of a Strategy and Action Plan for Strengthening Relations between Mafi a Island Marine Park and Local Communities. Tanzania: Consultancy Report.

13. Ngusaru A (2003) East African marine ecoregion. WWF web-based publication.

14. Katikiro R (2014) Reef fisheries and livelihoods in coastal villages of southern Tanzania: Lessons for adaptation to environmental change $\mathrm{Ph}$ D Dissertation Universität Bremen.

15. Tortell P, Ngatunga B (2007) Terminal Evaluation of the Development of Mnazi Bay Ruvuma Estuary Mariine Park project MBREMP.

16. Kamat V (2014) "The Ocean is our Farm”: Marine Conservation, Food Insecurity, and Social Suffering in Southeastern Tanzania" Human_Organization 73 (3).

17. Mwanjela G (2011) The Myth of Sustainable Livelihoods: A Case Study of the Mnazi Bay Marine Park in Tanzania. 